\title{
Hybrid Closed-loop therapy: Where are we in 2021?
}

\author{
Lalantha Leelarathna ${ }^{1}$, Pratik Choudhary ${ }^{2}$, Emma G Wilmot ${ }^{3,4}$, Alistair Lumb ${ }^{5,6}$ \\ Tim Street ${ }^{7}$, Partha $\operatorname{Kar}^{8} \&$ Sze May Ng${ }^{9,10}$
}

\footnotetext{
${ }^{1}$ Diabetes, Endocrinology and Metabolism Centre, Manchester University NHS Foundation Trust, Manchester, UK \& Division of Diabetes, Endocrinology and Gastroenterology, Faculty of Biology, Medicine and Health, University of Manchester, UK

${ }^{2}$ Leicester Diabetes Center, University of Leicester, Gwendolen Rd, Leicester LE5 4PW

${ }^{3}$ Royal Derby Hospital, University Hospitals of Derby and Burton NHS FT, Derby UK

${ }^{4}$ University of Nottingham, Nottingham, UK

${ }^{5}$ OCDEM, Oxford University Hospitals NHS FT, Oxford, UK

${ }^{6}$ Oxford NIHR Biomedical Research Centre, Oxford, UK

${ }^{7}$ Diabettech Ltd, London, UK

${ }^{8}$ Portsmouth Hospital NHS Trust, NHS England UK

${ }^{9}$ Paediatric Department, Southport and Ormskirk NHS Trust, Southport, UK

${ }^{10}$ Department of Women's and Children's Health, University of Liverpool, Liverpool, UK ORCID ID 0000-0002-3449-0541
}

Article Type: Invited Commentry

Word Count: 2000

Abstrect word count: 250 


\begin{abstract}
Hybrid closed-loop systems are characterised by the coexistence of algorithm driven automated insulin delivery combined with manual mealtime boluses. Used correctly, these insulin delivery systems offer better glucose control and reduced risk of hypoglycemia and represent the most advanced form of insulin delivery available for people with type 1 diabetes. This paper aims to compare the currently available commercial hybrid closed-loop systems in the UK: Medtronic 670G/780G, Tandem t:slim X2 Control IQ and CamAPS FX systems.

Medtronic 670G/780G systems use Guardian 3 sensor (7 day use, two to four calibrations / day) while Tandem and CamAPS systems use the calibration free Dexcom G6 sensor (10 days). CamAPS system is available as an android app while other two systems have the algorithm embedded in the insulin pump. During pivotal studies, depending on the study population and baseline $\mathrm{HbA1c}$, these systems achive \% time spent in the target range 3.9 to $10 \mathrm{mmol} / \mathrm{l}$ (70 to $180 \mathrm{mg} / \mathrm{dl}$ ) from $65 \%$ to $76 \%$ with low burden of hypoglycemia. All three systems allow for a higher glucose target for announced exercise while the Tandem system offers an additional night time tighter target. The CamAPS system offers fully customisable glucose targets and is the only system licenced for use during pregnancy. Additional education is required for both users and healthcare professionals to harness the best performance from these systems as well as trouble shoot when 'auto-mode'exists occur. We provide consensus recommendations to develop pragmatic pathways to guide patients, clinicians and commissioners in making informed decisions on the appropriate use of the diabetes technology.
\end{abstract}




\section{Introduction}

Type 1 diabetes is a lifelong endocrine condition related to insulin-deficiency caused by pancreatic beta-cell dysfunction ${ }^{1}$. People with type 1 diabetes therefore need to be able to self-adjust their insulin dose in order to achieve normoglycaemia and minimise the risk of micro and macrovascular complications. High blood glucose levels over time may cause complications associated with diabetes including damage to small and large blood vessels and nerves. Achieving glycaemic targets substantially reduces the risk of blindness, kidney failure, heart disease, stroke, and amputations ${ }^{2,3}$. Diabetes remains responsible for a large number of additional deaths, with the greatest relative risk in younger people ${ }^{4}$ There has been major progress of available technology in type 1 diabetes to support diabetes management including insulin pump therapy, intermittently scanned glucose monitoring and real-time glucose monitoring, as well as increasing access to structured education in the context of advances in T1 diabetes care ${ }^{5}$. Despite this, less than $10 \%$ reach a target HbA1c level of $6.5 \%$ (48 $\mathrm{mmol} / \mathrm{mol})$, about $20 \%$ reach a level below $7.0 \%(53 \mathrm{mmol} / \mathrm{mol})$ and less than $35 \%$ achive a target of $7.5 \%(59 \mathrm{mmol} / \mathrm{mol})$ or below based on the UK National Diabetes Audit ${ }^{6}$. Similarly in the USA type 1 diabetes exchange, The American Diabetes Association (ADA) HbA1c goal of $<58 \mathrm{mmol} / \mathrm{mol}$ for youth was achieved by only $17 \%$ and the goal of $<53 \mathrm{mmol} / \mathrm{mol}$ for adults by only $21 \%$. Mean HbA1c levels changed little between 2010-2012 and 2016-2018, except in adolescents who had a higher mean HbA1c in 2016-20187. Evolving technology offers the potential to improve glycaemic management reduce the above mentioned complications and the burden and risks of hypo \& hyperglycaemia, while improving quality of life.

Closed-loop insulin delivery systems (also known as 'artificial pancreas' systems) take the technology to the next level by integrating continuous glucose monitoring with an insulin pump and an algorithm which automates insulin delivery. Hybrid closed-loop systems are characterised by the coexistence of automated insulin delivery (via the algorithm) and user- 
initiated insulin delivery, for example, providing mealtime boluses. These insulin delivery systems offer better glucose control and reduced risk of hypoglycemia and represent the most advanced form of insulin delivery available for people with type 1 diabetes ${ }^{8-10}$. The objective of this paper is to compare the currently available commercial closed-loop systems in the UK thereby providing an up-to-date information for people living with type 1 diabetes and healthcare professionals to make an informed decision in a rapidly changing market.

\section{Current closed-loop system availability in UK}

Currently, three commercial closed-loop systems are available in the UK. In the order of introduction to UK market these are the Medtronic 670G system (and planned introduction of the 780G system in late 2020) (Minimed Medtronic, CA, USA), CamAPS FX, developed by CamDiab Ltd (www.camdiab.com, Cambridge, UK), and Tandem Control IQ system (Tandem Inc, USA). Medtronic and Tandem systems have the algorithm embedded in the pump software. In contrast CamAPS FX is a smartphone app, a home-use medical device, that manages glucose levels continuously and autonomously via Bluetooth connection to compatible insulin pump and glucose sensor. In addition to the commercially available products, as outlined below, people with type 1 diabetes are also using self-built DIY Artificial Pancreas Systems. These products are unlicenced and users take responsibility for any risks associated with use. Table 1 shows a comparison of the three commercial hybrid-closed loop systems currently available in the UK. 
Table 1. Current Commercial Hybrid Closed Loop Systems

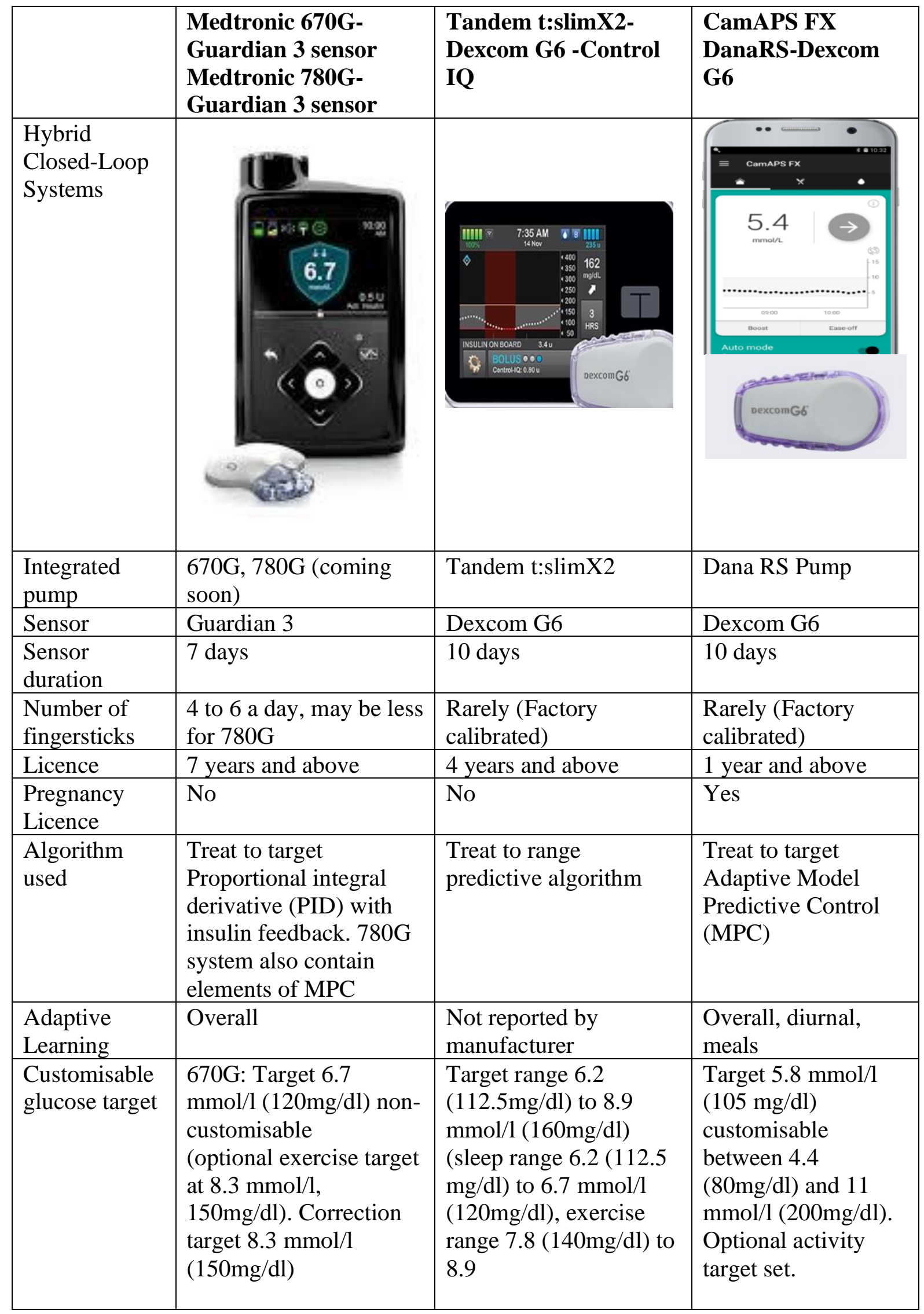




\begin{tabular}{|c|c|c|c|}
\hline & $\begin{array}{l}\text { 780G: Target } 6.7,6.1 \text { or } \\
5.5 \mathrm{mmol} / \mathrm{l} \text {. Correction } \\
\text { Target } 6 \mathrm{mmol} / \mathrm{l} \text {, } \\
\text { exercise Target } 8.3 \\
\mathrm{mmol} / \mathrm{l}\end{array}$ & $\begin{array}{l}\mathrm{mmol} / \mathrm{mol})(160 \mathrm{mg} / \mathrm{dl}) \\
\text { non-customisable. }\end{array}$ & \\
\hline $\begin{array}{l}\text { Exercise } \\
\text { Mode }\end{array}$ & Yes & Yes & Yes \\
\hline Boost Mode & No & No & Yes \\
\hline $\begin{array}{l}\text { Insulin } \\
\text { compatibility }\end{array}$ & Rapid only & Rapid only & Rapid \& ultra-rapid \\
\hline $\begin{array}{l}\text { Compatible } \\
\text { downloading } \\
\text { software }\end{array}$ & $\begin{array}{l}\text { Carelink } \\
\text { Manual downloading } \\
\text { required for } 670 \mathrm{G} \text {. } \\
\text { Automated app } \\
\text { compatibility with } 780 \mathrm{G}\end{array}$ & $\begin{array}{l}\text { Clarity (sensor data), } \\
\text { Diasend, Manual } \\
\text { downloading of pump } \\
\text { required }\end{array}$ & $\begin{array}{l}\text { Diasend } \\
\text { Automated } \\
\text { download }\end{array}$ \\
\hline $\begin{array}{l}\text { Automatic } \\
\text { cloud storage } \\
\text { of data }\end{array}$ & $\begin{array}{l}670 \mathrm{G} \text { no } \\
780 \mathrm{G} \text { yes }\end{array}$ & Dexcom yes, pump no & Yes, full system \\
\hline $\begin{array}{l}(\%) \text { Time in } \\
\text { Range (3.9 to } \\
10 \mathrm{mM}) \\
\text { achieved in } \\
\text { pivotal trials }\end{array}$ & $\begin{array}{l}\text { 670G:Adolescents } 67 \% \\
\text { (Baseline A1c 7.7\%) } \\
\text { and Adults 74\% } \\
\text { (Baseline A1c 7.3\%) } \\
11,12 \\
780 \mathrm{~g} \text { : Adolescents 73\% } \\
\text { (Baseline 7.6\%) and } \\
\text { Adults 75\% (Baseline } \\
\text { A1c 7.5\%) }{ }^{13}\end{array}$ & $\begin{array}{l}\text { Adolescents and adults } \\
71 \% \text { (age range } 14 \text { to } \\
71 \text { years, baseline A1c } \\
7.6 \% \text { ). Children } 67 \% \\
\text { (age range } 6 \text { to } 13 \\
\text { years, baseline A1c } \\
7.7 \%)^{14,15}\end{array}$ & $\begin{array}{l}\text { Well-controlled } \\
\text { adults (baseline A1c } \\
6.9 \% \text { ) TIR } 76 \% \\
\text { Poorly controlled } \\
\text { adults \& children } \\
\text { (baseline A1c 8.3\%) } \\
65-68 \%\end{array}$ \\
\hline Waterproofing & $\begin{array}{l}\text { Pump and transmitter } \\
\text { are waterproof. Sensor } \\
\text { is waterproof up to } 12 \\
\text { feet for up to } 24 \text { hours }\end{array}$ & $\begin{array}{l}\text { Pump is waterproof for } \\
\text { up to } 3 \text { feet for } 30 \\
\text { minutes and transmitter } \\
\text { are waterproof for } 8 \\
\text { feet }\end{array}$ & $\begin{array}{l}\text { Pump is fully } \\
\text { waterproof (IPX8) } \\
\text { and transmitter is } \\
\text { waterproof for } 8 \text { feet }\end{array}$ \\
\hline $\begin{array}{l}\text { Approximate } \\
\text { Yearly Cost in } \\
\text { UK NHS** }\end{array}$ & $\begin{array}{l}\text { Pump }=£ 612.50 \\
\text { Consumables }=£ 1400 \\
\text { Medtronic Sensor } \\
=£ 3186 \\
\text { SMBG }=£ 500 \\
\text { App }=£ 0 \\
\text { Total Yearly Cost if } \\
\text { new to pump }=£ 5698.50\end{array}$ & $\begin{array}{l}\text { Pump }=£ 838 \\
\text { Consumables }=£ 1588 \\
\text { Dexcom G6 } \\
\text { sensor }=£ 2645 \\
\text { SMBG }=£ 100 \\
\text { App }=£ 0 \\
\text { Total Yearly Cost if } \\
\text { new to pump }=£ 5171\end{array}$ & $\begin{array}{l}\text { Pump }=£ 575 \\
\text { Consumables }=£ 1400 \\
\text { Dexcom G6 } \\
\text { sensor }=£ 2645 \\
\text { SMBG }=£ 100 \\
\text { App }=£ 840 \\
\text { Total Yearly Cost if } \\
\text { new to pump }=£ 5560\end{array}$ \\
\hline $\begin{array}{l}\text { Yearly } \\
\text { additional cost } \\
\text { if already on } \\
\text { pump }\end{array}$ & $\begin{array}{l}\text { Cost of sensors } \\
£ 3186\end{array}$ & $\begin{array}{l}\text { Cost of sensors + extra } \\
\text { cost of control IQ pump } \\
\text { - savings from reduced } \\
\text { SMBG) } \\
(2645+50-400)=£ 2295\end{array}$ & $\begin{array}{l}\text { Cost of sensors }+ \\
\text { extra cost of App - } \\
\text { savings from } \\
\text { reduced SMBG } \\
2645+840- \\
400=£ 3045\end{array}$ \\
\hline
\end{tabular}




\begin{tabular}{|c|c|c|c|}
\hline Advantages & $\begin{array}{l}\text { Well established pump } \\
\text { Robust training and } \\
\text { support } \\
\text { Strong clinical } \\
\text { experience with } 670 \mathrm{G} \\
\text { closed loop }\end{array}$ & $\begin{array}{l}\text { Strong evidence base } \\
\text { No need for fingerstick } \\
\text { Attractive pump } \\
\text { interface } \\
\text { Online training for } \\
\text { HCPs and users }\end{array}$ & $\begin{array}{l}\text { Strong evidence base } \\
\text { No need for } \\
\text { fingerstick } \\
\text { Wide age range and } \\
\text { pregnancy licence } \\
\text { Mobile app with } \\
\text { customisable targets } \\
\text { Bolusing from phone } \\
\text { for added privacy } \\
\text { Online training for } \\
\text { HCPs and users }\end{array}$ \\
\hline Disadvantages & $\begin{array}{l}\text { Limited RCT evidence. } \\
\text { Need for multiple } \\
\text { finger-sticks, relatively } \\
\text { conservative system } \\
\text { Alarm fatigue with } \\
\text { substantial } \\
\text { discontinuation rates } \\
\text { Auto mode exists with } \\
\text { 670G which is likely to } \\
\text { improve with } 780 \mathrm{G}\end{array}$ & $\begin{array}{l}\text { Limited real-world } \\
\text { clinical experience with } \\
\text { the system as recently } \\
\text { launched } \\
\text { Cannot revert to } \\
\text { previous basal suspend } \\
\text { mode if closed-loop is } \\
\text { not suitable } \\
\text { Not compatible with } \\
\text { faster-acting insulins } \\
\text { Relies on users' basal } \\
\text { rates, carb ratio and } \\
\text { corrections }\end{array}$ & $\begin{array}{l}\text { Limited real-world } \\
\text { clinical experience } \\
\text { with the system as } \\
\text { recently launched } \\
\text { App only available } \\
\text { for Androids } \\
\text { Need to carry the } \\
\text { phone. } \\
\text { Loss of Dexcom } \\
\text { follow feature at } \\
\text { present but "follow" } \\
\text { planned later this } \\
\text { year } 2020 .\end{array}$ \\
\hline
\end{tabular}

**Prices are approximate in GBP based in the UK NHS and are correct at the time of

publication, but these prices could vary in different countries. 
Figure 1: Recommendation of hybrid-closed-loop therapy in the Diabetes Technology

Pathway. Adapted from the Diabetes UK position statement

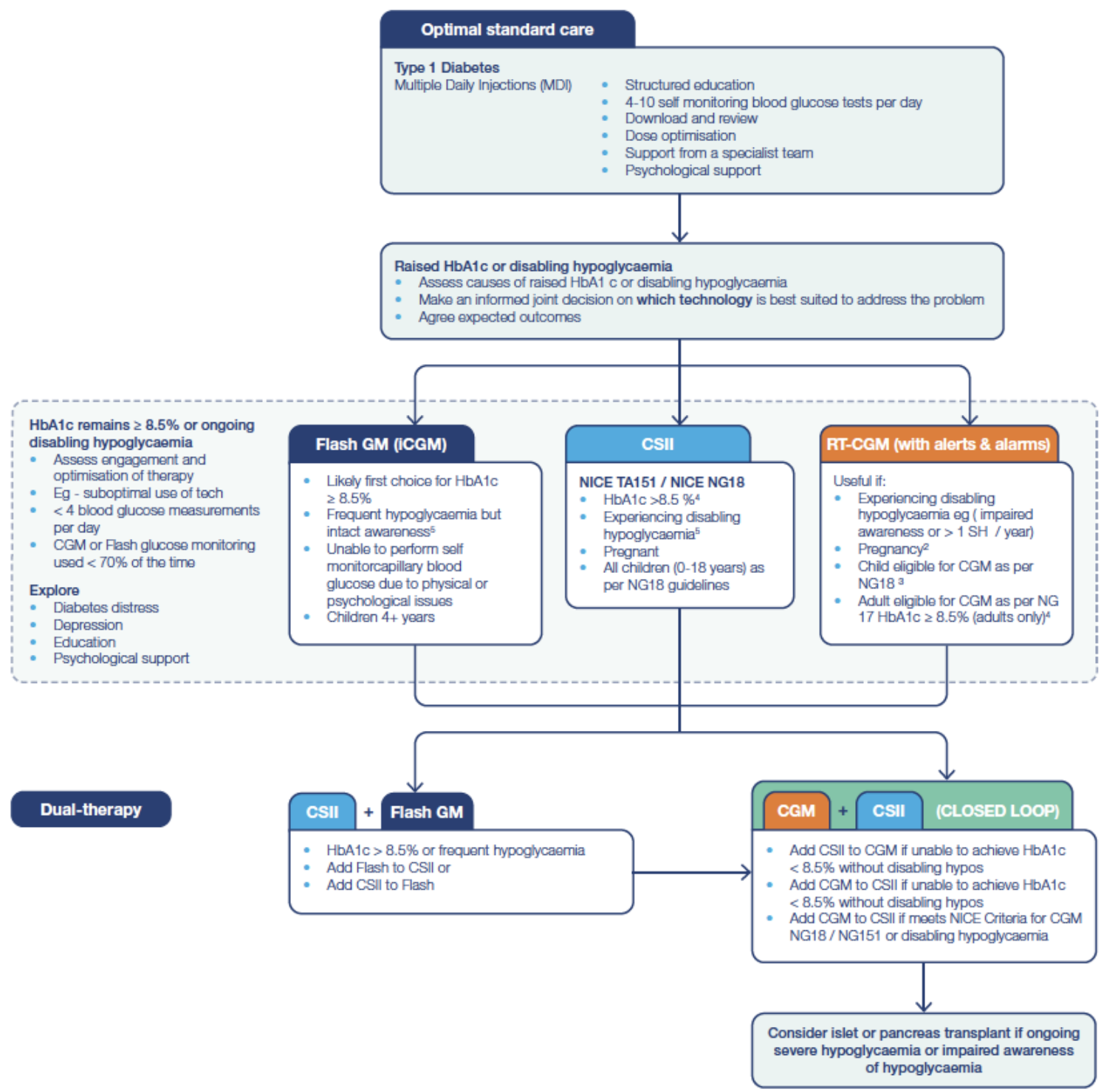

Figure 1 detail a pragmatic pathway with particular relevance to funding constraints within the UK healthcare system which is adapted from the Type 1 diabetes technology pathway ${ }^{19}$. At present, there is no international data to highlight the variations in the use of HCL systems and current global access is constrained by funding challenges. 


\section{Open Source Closed Loop systems}

While commercial offerings have appeared in the past two years, there has been a vibrant community of people with type 1 diabetes writing their own insulin dosing algorithms that work with existing pump technology and releasing the code to open source repositories making it freely available for others to build ${ }^{20-23}$. These are commonly known as DIY Artificial Pancreas Systems (DIYAPS). As of writing, there are over 4,700 people worldwide using the various systems, with the preferred choice of system varying by geography depending on availability of different pumps. There are three systems available: OpenAPS (2015, running on small Linux computer); AndroidAPS (2017, running the same algorithm as OpenAPS on an Android phone) and Loop (2016, running on iPhone with RileyLink to talk to pumps $)^{20}$. In the UK, the most popular is AndroidAPS (used by $66 \%$ of users) due to the range of pumps and CGMs it works with. Various retrospective studies have shown that through the use of DIYAPS, there are reductions in $\mathrm{HbA}_{1} \mathrm{C}$ and increases in Time in Range and that the glycemic benefit of DIYAPS is in reducing hyperglycemia without compromising the low occurrence of hypoglycemia ${ }^{20}$.

\section{Discussion}

New and improved hybrid closed-loop technologies for the treatment of diabetes are continuing to emerge at an impressive rate. The Pivotal Omnipod Horizon ${ }^{\mathrm{TM}}$ Automated Glucose Control System clinical trials are currently underway and are due to be completed in December $2021^{24}$ as well as the Insulin Only Bionic Pancreas (iLET) Pivotal Trial ${ }^{25}$. Another closed-loop system current in use in France is the Diabeloop system ${ }^{26,}{ }^{27}$. The DBLG1 algorithm developed by Diabeloop is hosted on a dedicated handset and acts as a user interface. It is connected to a continuous glucose monitoring (CGM) and an insulin pump. The DBLG1 artificial intelligence analyzes the data in real time, while considering the patient's physiology, 
history and data entries (meals or exercise) to determine the correct dose of insulin to administer.

At present, hybrid closed loops do not "automate" diabetes management but are likely to mostly benefit motivated individuals who are committed to maximise the clinical benefit. The need for appropriate education to maximise benefits of novel diabetes technology is well established. ${ }^{28}$ Some education is common to most novel diabetes technology - for example need to count carbohydrates and deliver meal bolus with food. In addition there is also need for specific education with hybrid closed-loop systems: for example how to deal with \& minimize with auto mode exists, dealing with connection problems \& software issues and updates and how to safely use standard sensor augmented pump therapy at times when closedloop is not working for what ever reasons ${ }^{29,30}$. Users and healthcare professionals also need to be educated about interpretation of data outputs from various closed-loop software systems and how to adjust exisiting pump seetings based on closed-loop performance. Optimimal user settings are more critical for some systems for example Tandem Control-IQ than other systems like CamAPS. For some individuals, such technology may be an additional burden of care as reported in some studies where there has been a high rate of "auto-mode" exits while using the hybrid closed loop functions ${ }^{31,32}$. It is important for future trials to focus on higher-risk populations such as those with persistently high $\mathrm{HbA1c}$ and/or low socioeconomic status to ensure that a skewed evidence base does not develop to exacerbate existing socioeconomic disparities in health outcomes and access to advanced technology. The success of diabetes technology implementation should emphasise on the importance of creating technology which places the lowest possible demands on the user and to minimise disparities in access. Ultimately, the goal in the future would be to provide full closed loop systems to all people living with type 1 diabetes. 


\section{Summary}

As technology for insulin delivery systems continues to advance rapidly, healthcare professionals need to stay current to better guide their patients and provide the necessary education, support and patient choice when accessing appropriate technology. Digital revolutions in diabetes management will continue to progress, however digital gaps continue to exist with variations in care between areas of least and most socially deprived populations. This paper aims to develop robust and pragmatic pathways and information to guide clinicians and commissioners in making informed decisions on the most appropriate use of diabetes technology. 


\section{References:}

1. Daneman D. Type 1 diabetes. Lancet. 2006;367(9513):847-858.

2. Nathan DM, Genuth S, Lachin J, et al. The effect of intensive treatment of diabetes on the development and progression of long-term complications in insulin-dependent diabetes mellitus. $N$ Engl J Med. 09 1993;329(14):977-86. doi:10.1056/NEJM199309303291401

3. Nathan DM, Cleary PA, Backlund JY, et al. Intensive diabetes treatment and cardiovascular disease in patients with type 1 diabetes. N Engl J Med. Dec 2005;353(25):2643-53. doi:10.1056/NEJMoa052187

4. Rawshani A, Sattar N, Franzén S, et al. Excess mortality and cardiovascular disease in young adults with type 1 diabetes in relation to age at onset: a nationwide, register-based cohort study. Lancet. 08 2018;392(10146):477-486. doi:10.1016/S0140-6736(18)31506-X

5. Tauschmann M, Hovorka R. Technology in the management of type 1 diabetes mellitus current status and future prospects. Nat Rev Endocrinol. 08 2018;14(8):464-475. doi:10.1038/s41574018-0044-y

6. NHS Digital: National Diabetes Audit reports available at: https://digital.nhs.uk/data-andinformation/publications/statistical/national-diabetes-audit.

7. Foster NC, Beck RW, Miller KM, et al. State of Type 1 Diabetes Management and Outcomes from the T1D Exchange in 2016-2018. Diabetes Technol Ther. 02 2019;21(2):66-72. doi:10.1089/dia.2018.0384

8. Bekiari E, Kitsios K, Thabit H, et al. Artificial pancreas treatment for outpatients with type 1 diabetes: systematic review and meta-analysis. BMJ. Apr 2018;361:k1310.

9. Weisman A, Bai JW, Cardinez M, Kramer CK, Perkins BA. Effect of artificial pancreas systems on glycaemic control in patients with type 1 diabetes: a systematic review and meta-analysis of outpatient randomised controlled trials. Lancet Diabetes Endocrinol. Jul 2017;5(7):501-512. doi:10.1016/S2213-8587(17)30167-5

10. Karageorgiou V, Papaioannou TG, Bellos I, et al. Effectiveness of artificial pancreas in the non-adult population: A systematic review and network meta-analysis. Metabolism. 01 2019;90:2030. doi:10.1016/j.metabol.2018.10.002

11. Bergenstal RM, Garg S, Weinzimer SA, et al. Safety of a Hybrid Closed-Loop Insulin Delivery System in Patients With Type 1 Diabetes. JAMA. 10 2016;316(13):1407-1408. doi:10.1001/jama.2016.11708

12. Garg SK, Weinzimer SA, Tamborlane WV, et al. Glucose Outcomes with the In-Home Use of a Hybrid Closed-Loop Insulin Delivery System in Adolescents and Adults with Type 1 Diabetes. Diabetes Technol Ther. 03 2017;19(3):155-163. doi:10.1089/dia.2016.0421 
13. Carlson A, Bode B, Brazg R, et al. Safety and Glycemic Outcomes of the MiniMed Advanced Hybrid Closed-Loop (AHCL) System in Subjects with T1D. Diabetes. 2020;69 (Supplement 1)(June)(Supplement 1)

14. Brown SA, Kovatchev BP, Raghinaru D, et al. Six-Month Randomized, Multicenter Trial of Closed-Loop Control in Type 1 Diabetes. N Engl J Med. 10 2019;381(18):1707-1717. doi:10.1056/NEJMoa1907863

15. Breton MD, Kanapka LG, Beck RW, et al. A Randomized Trial of Closed-Loop Control in Children with Type 1 Diabetes. N Engl J Med. 08 2020;383(9):836-845.

doi:10.1056/NEJMoa2004736

16. Bally L, Thabit H, Kojzar H, et al. Day-and-night glycaemic control with closed-loop insulin delivery versus conventional insulin pump therapy in free-living adults with well controlled type 1 diabetes: an open-label, randomised, crossover study. Lancet Diabetes Endocrinol. Apr 2017;5(4):261-270. doi:10.1016/S2213-8587(17)30001-3

17. Thabit H, Tauschmann M, Allen JM, et al. Home Use of an Artificial Beta Cell in Type 1 Diabetes. N Engl J Med. Nov 2015;373(22):2129-2140. doi:10.1056/NEJMoa1509351

18. Tauschmann M, Thabit H, Bally L, et al. Closed-loop insulin delivery in suboptimally controlled type 1 diabetes: a multicentre, 12 -week randomised trial. Lancet. 10 2018;392(10155):1321-1329. doi:10.1016/S0140-6736(18)31947-0

19. Choudhary P, Campbell F, Joule N, Kar P, UK D. A Type 1 diabetes technology pathway: consensus statement for the use of technology in Type 1 diabetes. Diabet Med. 05 2019;36(5):531538. doi:10.1111/dme.13933

20. Kesavadev J, Srinivasan S, Saboo B, Krishna B M, Krishnan G. The Do-It-Yourself Artificial Pancreas: A Comprehensive Review. Diabetes Ther. Jun 2020;11(6):1217-1235. doi:10.1007/s13300020-00823-z

21. Dowling L, Wilmot EG, Choudhary P. Do-it-yourself closed-loop systems for people living with type 1 diabetes. Diabet Med. May 2020;doi:10.1111/dme.14321

22. Crabtree TSJ, Choudhary P, Hammond P, Lumb A, McLay A, Wilmot EG. Health-care professional opinions of DIY artificial pancreas systems in the UK. Lancet Diabetes Endocrinol. 03 2020;8(3):186-187. doi:10.1016/S2213-8587(19)30417-6

23. Wilmot EG, Danne T. DIY artificial pancreas systems: the clinician perspective. Lancet Diabetes Endocrinol. 03 2020;8(3):183-185. doi:10.1016/S2213-8587(19)30416-4

24. Clinical Trials Registry https://clinicaltrials.gov/ct2/show/NCT04196140.

25. Clinical Trials Registry. https://clinicaltrials.gov/ct2/show/NCT04200313.

26. Benhamou PY, Lablanche S, Vambergue A, Doron M, Franc S, Charpentier G. Patients with highly unstable type 1 diabetes eligible for islet transplantation can be managed with a closed-loop 
insulin delivery system: A series of N-of-1 randomized controlled trials. Diabetes Obes Metab. Oct 2020;doi:10.1111/dom.14214

27. Hanaire H, Franc S, Borot S, et al. Efficacy of the Diabeloop closed-loop system to improve glycaemic control in patients with type 1 diabetes exposed to gastronomic dinners or to sustained physical exercise. Diabetes Obes Metab. 03 2020;22(3):324-334. doi:10.1111/dom.13898

28. De Ridder F, den Brinker M, De Block C. The road from intermittently scanned glucose monitoring to hybrid closed-loop systems: Part A. Keys to success: subject profiles, choice of systems, education. Ther Adv Endocrinol Metab. 2019;10:2042018819865399.

doi:10.1177/2042018819865399

29. Duffus SH, Ta'ani ZA, Slaughter JC, Niswender KD, Gregory JM. Increased proportion of time in hybrid closed-loop "Auto Mode" is associated with improved glycaemic control for adolescent and young patients with adult type 1 diabetes using the MiniMed 670G insulin pump. Diabetes Obes Metab. 04 2020;22(4):688-693. doi:10.1111/dom.13912

30. Akturk HK, Giordano D, Champakanath A, Brackett S, Garg S, Snell-Bergeon J. Long-term real-life glycaemic outcomes with a hybrid closed-loop system compared with sensor-augmented pump therapy in patients with type 1 diabetes. Diabetes Obes Metab. 04 2020;22(4):583-589. doi:10.1111/dom.13933

31. Messer LH, Berget C, Vigers T, et al. Real world hybrid closed-loop discontinuation: Predictors and perceptions of youth discontinuing the 670G system in the first 6 months. Pediatr Diabetes. 03 2020;21(2):319-327. doi:10.1111/pedi.12971

32. Lal RA, Basina M, Maahs DM, Hood K, Buckingham B, Wilson DM. One Year Clinical Experience of the First Commercial Hybrid Closed-Loop System. Diabetes Care. 12 2019;42(12):2190-2196. doi:10.2337/dc19-0855 